\title{
AN APPROACH TO MONITORING INFLUENZA VACCINATION UPTAKE ACROSS EUROPE
}

\author{
M. Kroneman (m.kroneman@nivel.nl) ${ }^{1}$, W J Paget ${ }^{2}$, L. E. Meuwissen², C Joseph ${ }^{3}$, H Kennedy ${ }^{4}$ \\ 1. Nederlands instituut voor onderzoek van de gezondheidszorg (NIVEL, the Netherlands Institute for Health Services Research), \\ Utrecht, the Netherlands \\ 2. European Influenza Surveillance Scheme (EISS) coordination centre, Utrecht, the Netherlands \\ 3. Respiratory Diseases Department, Health Protection Agency, Centre for Infections, London, United Kingdom \\ 4. Health Protection Agency CDSC, Belfast, Northern Ireland
}

Currently, the monitoring of influenza vaccination uptake is mainly a national issue. As influenza infection easily crosses international borders, it is in the interest of all countries to have a high vaccine uptake in people who may be vulnerable when influenza spreads. A Europe-wide monitoring system can provide insight into the strengths and weaknesses of uptake rates in countries and, once sufficient levels are achieved, can safeguard the continuation of the achieved levels. This paper aims to address the following issues: a) How is influenza vaccination uptake monitored in Europe? b) What methods to monitor vaccination uptake are available and what are their limitations? c) What steps should be taken to implement a European-wide influenza vaccination uptake monitoring system?

Based on existing literature and experiences in monitoring influenza vaccination uptake, an approach to set up a European-wide monitoring system is proposed.

The following issues were identified as relevant for influenza vaccination uptake monitoring: a) Agreement on the population groups in which vaccination uptake should be monitored; b) The frequency of data collection; c) The importance of sharing experiences regarding existing influenza vaccination campaigns in order to learn from each other, and develop 'best practices'; d) The need to publish uptake data in close relation with influenza surveillance data and other European efforts on dissemination of vaccination knowledge.

To stimulate the discussion on implementing a pan-European influenza uptake monitoring scheme the following recommendations were suggested : a) Develop a common set of variables; b) Build on experience from individual countries; c) Create a coordinating body; d) Create or identify a platform to publish the data; e) Start small and expand rapidly.

\section{Introduction}

Monitoring influenza vaccination uptake in the population is important for several reasons. Firstly, influenza vaccination has an effect on the health of the population: it is generally assumed to prevent premature deaths and reduce the burden of disease [1-9]. However, some critical studies have been published recently concerning selection bias, which may have led to more favourable outcomes for vaccine effectiveness in community-dwelling elderly people [10-12]. Secondly, as a public health intervention associated with considerable resources and costs, influenza vaccination campaigns need to be monitored and evaluated. Finally, information on influenza vaccination uptake is needed because of the current pandemic threat: countries should have an existing and well functioning distribution channel for influenza vaccinations in the inter-pandemic period in order to be able (potentially) to use part of this infrastructure to distribute vaccines in a pandemic situation.

Currently, monitoring influenza vaccination uptake is mainly a national issue. Although almost all European countries have national recommendations for influenza vaccination [13], not all countries are able to provide data on uptake of all the groups for whom the vaccination is recommended [14]. Attempts to provide international overviews of uptake rates have so far been on an ad hoc basis: Van Essen et al. used sales figures to calculate vaccination uptake in the population [13-15]. This is the only European-wide attempt to monitor trends in vaccination uptake, but it does not provide insight into the uptake rates for high-risk persons. In some countries, comparative population surveys have been carried out, either on an ad hoc basis (Netherlands, Germany, Poland, Sweden and Spain [16]) or annually (Belgium, France, Italy, Germany, Spain and United Kingdom [17]).

As influenza infection easily crosses international borders, it is in the interest of all countries to have high vaccine uptake in people who may be vulnerable when influenza spreads. A Europeanwide monitoring system can provide insight into the strengths and weaknesses of the vaccination campaigns of each country. Once sufficient levels are achieved, the monitoring system contributes to safeguarding the continuation of the achieved levels and provides complementary information to already existing European public health monitoring efforts such as the European Influenza Surveillance Scheme (EISS, http://www.eiss.org/index.cgi) [18] and the Vaccine European New Integrated Collaboration Effort (VENICE, http://venice.cineca.org/) [19].

This paper addresses the following issues:

- How is influenza vaccination uptake monitored in Europe?

- What methods to monitor vaccination uptake are available and what are their limitations?

- What steps should be taken to implement a European-wide influenza vaccination uptake monitoring system?

The aim of this paper is not to provide straightforward answers, but to stimulate discussion by proposing one possible approach to the development of a European influenza vaccination monitoring system. 


\section{Existing monitoring efforts in Europe}

Most countries in Europe have some form of influenza vaccination monitoring system. In 2001, 70\% of 27 European countries (EU-25 Member States, Norway and Switzerland) had such a system [14]. This may range from ad hoc surveys to advanced information systems involving general practitioners (GPs) who provide detailed monthly data. In some countries the monitoring systems may also vary by region. For instance in the United Kingdom (UK), annual data are available from the GP-registration forms in paper copies only in Northern Ireland [20,21], whereas in England there is a web-based system that provides monthly data and is even capable of daily reports $[22,23]$. In some other countries, different methods may coexist, as in the Netherlands, where both ad hoc population surveys and data from the GP information networks are available $[24,25]$.

The level of detail of monitoring also differs across countries. Almost $70 \%$ of those that have a monitoring system are able to provide uptake rates for the elderly. The percentage of countries that can provide uptake rates for those suffering from chronic conditions who are younger than 65 years is much lower [14]. However, for most countries in Europe there is currently no internationally available information about the monitoring systems used, the frequency of collecting the data and the responsible institutions.

\section{Strengths and weaknesses of different methods used to monitor} influenza uptake

Several methodologies are available for collecting data on influenza vaccine uptake. Their appropriateness depends on the existing health care and vaccine distribution systems. Information may be collected by means of population surveys, physician information networks, information networks of other health care workers or vaccine sales data.

\section{Population surveys}

Method: Population surveys are based on questionnaires that are conducted among a representative sample of the total population. This can be done either by telephone, by mail or face-to-face. Population surveys are independent of the way the health care system is organised.

Limitations: The data on both influenza vaccination uptake and belonging to a high-risk group depend on self-reported data, which cannot be verified by medical records. Previous research revealed that for both vaccination uptake and chronic conditions, self-reported data appear to be sufficiently reliable [26-30]. A significant problem with population surveys is that large numbers of respondents are needed to obtain data on specific high-risk groups. Other limitations, which often make comparisons between countries difficult, include different sampling methods used and different timing and frequency of health surveys in different countries. In addition, population surveys often a priori exclude institutionalised populations, such as residents of nursing homes, who are among risk groups often targeted by influenza vaccination recommendations.

\section{Physician information networks}

Method: Physician information networks can also be used to collect vaccination uptake data [26]. In this case, GPs and/or specialists register each vaccine they administer.

Limitations: This approach depends on the following conditions: the vaccine is administered mainly by physicians; vaccination uptake is registered and chronic conditions are accurately coded according to an internationally recognised system (like the International Classification of Primary Care - ICPC); Besides this, physicians included in the network should act as gatekeepers in the existing health system, that is the patient population has to be registered with individual GPs or practices and the GPs should manage the medical records of their patients. This latter condition is necessary to obtain a population denominator. Furthermore, a system to collate and process these data needs to be established. Other limitations of physician information networks include possible miscoding of vaccinations and potential problems with obtaining access to such data by third parties for confidentiality reasons. Currently, many European Union (EU) countries are piloting electronic patient record systems, which have great potential for monitoring of vaccination coverage. However, again, there are substantial differences in the structure and functioning of these recording systems between regions and countries. Different systems within a country may hinder the merging and analysing of data at national level; different systems between countries may complicate international comparisons. Furthermore, the GP registration networks do not monitor influenza vaccination outside the traditional health care setting, such as employee vaccination campaigns organised by large companies or shopping centres.

\section{Vaccine sales data}

Method: Vaccine sales data can be used to estimate the overall population vaccination rates [13].

Limitations: This method requires the implementation of careful procedures to ensure the cooperation of vaccine manufactures to provide confidential sales figures. Besides this, the sales figures do not give insight into the vaccine coverage rates of the respective risk groups.

\section{Information networks of other health care workers}

Method: Information networks of other health care workers may also be able to provide uptake data, such as vaccination sales by pharmacists.

Limitations: It is not clear to what extent health care workers other than physicians are able to provide data on, for instance, chronic conditions and to what extent a reliable population denominator can be established.

\section{Which method is best?}

It should be stressed that not all methods are appropriate for all countries because of differences in the health care systems. In addition, it may be difficult for countries to change their existing monitoring systems, should such need arise for the sake of international comparisons, because the existing systems probably fit best in the health care system and/or because changing the monitoring system may have financial consequences. Presently, an answer to the question 'Which method is best?' cannot be given. It is possible to use different data collection methods, choosing the most suitable one for each country. However, in this case one needs to know the bias resulting from each system. An ad hoc comparison between the GP information system data and postal survey data in the Netherlands revealed that the GP information network provided a $10 \%$ higher uptake rate estimate than the postal survey [31].

Another relevant issue is the costs of the data collection. It is currently not clear which method is the most cost-effective. This may differ per country and depend on the health care system, existing monitoring systems, etc. 
Furthermore, it is important to realise that all methods appear to, a priori, exclude parts of the population.

\section{Relevant issues and conditions for a European monitoring} system

For the development of a European-wide influenza vaccination monitoring system, several basic questions need to be addressed:

In what population groups should vaccination uptake be monitored?

Problem: In order to be able to know to what extent the highrisk population is vaccinated, it is important to define the highrisk groups and to explore the feasibility of gathering data on these groups. A basic question is whether the information at a European level should be uniform, with comparable groups for all countries, or could be country-specific, adjusted to the national recommendations. With the first type of information, cross-country comparisons would be possible, with the second type of information the countries' ability to fulfil their own policy recommendations would be monitored and could result in getting more reliable figures for the overall uptake in the recommended groups.

Possible solution: There should be an agreement about the minimal set of information and level of detail that needs to be collected in each country for proper monitoring. Preferably, the aim should be to achieve a monitoring system that satisfies both international and country-level information needs on vaccine uptake. The issues to consider here may be for instance whether the age limit for the elderly should be 55 or 65 years, or whether to include children, when the groups for whom vaccination is recommended differ among countries. These issues may lead to a discrepancy between an international agreed dataset to be collected and the national available dataset. Preferably this discrepancy should be as small as possible.

\section{Who should be involved in registering?}

Problem: Different health professionals and organisations may be involved in influenza vaccination administering. Several influenza vaccination campaigns may run simultaneously, targeting partly overlapping populations, e.g. vaccinating employees by large companies and vaccinating high-risk persons by GPs.

Possible solution: for each possible administrator an inventory should be made from the information they are able to provide on vaccinated individuals and clear procedures need to be developed on how this information should be registered. However, this does not solve the denominator problem, which remains a serious one.

Furthermore, it is important to ensure completeness of the data collection, in order to avoid underestimation of the influenza vaccination uptake.

\section{Frequency of data collection}

Problem: It currently seems logical to collect influenza uptake data on a yearly basis, since the vaccination is a yearly event. However, a higher frequency can be advocated, especially during the vaccination season, in order to be able to intervene when it seems that a pre-set target may not be reached that season. On the other hand, for countries with satisfactory and stable uptake levels (e.g. countries that already meet the WHO recommendation of attaining vaccination coverage of the elderly population of at least $75 \%$ by 2010 [32]), a two-yearly monitoring might be sufficient. There may also be differences between national frequencies of data collection and the frequency needed for data at a European level.

Possible solution: A minimum level of frequency should be defined, which should eventually expand towards a more detailed monitoring.

\section{Insight into existing influenza vaccination campaigns}

Problem: Differences in uptake rates do not provide insight into why some countries have higher vaccine coverage compared to others. In order to learn from each other, countries should share experiences, to be able to develop best practices.

Possible solution: This can be done by collecting information for each country on the ways the vaccine is distributed and administered, and the means of informing the public. This information, in combination with the influenza vaccination uptake data, can reveal the practical barriers that hinder vaccination in different countries.

\section{Publication of the data}

Problem: It would seem sensible to present all influenza-related data in one place. However, this raises the question of who should provide the data and what quality checks would be necessary, before data may be published.

Possible solution: The uptake data may be published in close relation with influenza surveillance data (e.g. by EISS and the European Centre for Disease Prevention and Control (ECDC)) and the output of other European efforts on dissemination of vaccination knowledge, such as the VENICE project [19]. However, a formal agreement would be needed for each country regarding the persons/ institutions responsible for submitting and validating data before publication.

Recommendations for implementing a monitoring scheme for influenza vaccination uptake

The following are the steps we think need to be taken to successfully implement a European-wide monitoring system:

\section{Develop a common set of variables}

Questions about the level of detail and the frequency of data collection should be addressed. A set of targets should be defined to give direction to the way the scheme should develop, including variables for defining the risk groups to be included and methods of data collection. These targets should describe the final desired situation for the monitoring scheme. A minimum set of requirements for the monitoring system that is both useful at a European level and feasible for countries that will join the scheme should be established. We propose that a group of national experts from across Europe should deal with these questions.

\section{Build on experience from individual countries}

Many countries collect at least some information on influenza vaccination uptake. For each country, the organisation that is responsible for monitoring influenza vaccination uptake and the contact persons within these organisations should be involved in the scheme. Building on existing efforts is likely to be cheaper and more effective and will have a better chance of becoming a stable and continuous way of providing data compared to introducing a complete new system that may need new ways of data collection. At a later stage, harmonisation of the monitoring methods can be targeted. Various methods of data collection can be used, as long as they are properly described and their limitations known. Allowing different methods increases the possibility of using existing national data collection methods, which may be adjusted to the desired data format in an incremental way, instead of having to develop and institutionalise new methods of data collection.

\section{Create a coordinating body}

At a European level, a coordinating body is necessary to collect and disseminate the data. This body should preferably work closely 
with existing efforts in influenza surveillance. It can also carry out research on vaccination uptake in Europe and work on vaccination recommendations.

\section{Create or identify a platform to publish the data}

To make the data available for a wide public a platform to publish the data should be available. This platform should be easily accessible and highly visible. It could be, for instance, a website linked with existing influenza surveillance data (e.g. ECDC, EISS).

\section{Start small and expand rapidly}

When the harmonised set of data is agreed, we suggest the monitoring system be tested in a few countries with a limited data set (e.g. collecting only data for uptake among the elderly). These countries should preferably have different types and quality of their national monitoring systems in order to be able to identify and tackle all kinds of problems at this early stage. With the lessons learned from these countries, the next step would be to extend the network in a stepwise manner so that eventually influenza vaccination uptake data will be available for all countries in Europe, and a European monitoring system will be put in place.

\section{Conclusions}

Influenza vaccination uptake monitoring is a 'forgotten' subject in the EU, which is strange in the light of the costs that come with the vaccination programmes and the discussion of expanding of the recommendations for this vaccination. This paper does not provide ready answers in the sense of a fully developed proposal for such a monitoring system, but rather highlights the problems likely to be encountered when developing such a system, and describes a possible route towards a uniform monitoring system. It aims to increase the awareness of this important albeit neglected subject and inspire discussions on this issue.

\section{References}

1. Hak E, Buskens E, van Essen GA, de Bakker DH, Grobbee DE, Tacken MA, et at. Clinical effectiveness of influenza vaccination in persons younger than 65 years with high-risk medical conditions: the PRISMA study. Arch Intern Med. 2005;165(3):274-80.

2. Nichol KL, Nordin J, Mullooly J. Influence of clinical outcome and outcome period definitions on estimates of absolute clinical and economic benefits of influenza vaccination in community dwelling elderly persons. Vaccine. 2006;24(10):1562-8

3. Jefferson TO, Rivetti D, Di Pietrantonj C, Rivetti A, Demicheli V. Vaccines for preventing influenza in healthy adults. Cochrane Database Syst Rev. 2007;(2):CD001269.

4. Ortqvist A, Granath F, Askling J, Hedlund J. Influenza vaccination and mortality: prospective cohort study of the elderly in a large geographical area. Eur Respir J. 2007;30(3):414-22.

5. Nichol KL, Nordin JD, Nelson DB, Mullooly JP, Hak E. Effectiveness of influenza vaccine in the community-dwelling elderly. $\mathrm{N}$ Engl J Med. 2007;357(14):1373-81.

6. Hak E, Hoes AW, Verheij TJ. Influenza vaccinations: who needs them and when? Drugs. 2002;62(17):2413-20.

7. Monto AS. Preventing influenza in healthy adults: the evolving story. JAMA. 2000;284(13):1699-701.

8. Christenson B, Lundbergh P. Comparison between cohorts vaccinated and unvaccinated against influenza and pneumococcal infection. Epidemiol Infect. 2002;129(3):515-24

9. Gross PA, Hermogenes AW, Sacks HS, Lau J, Levandowski RA. The efficacy of influenza vaccine in elderly persons. A meta-analysis and review of the literature. Ann Intern Med. 1995;123(7):518-27.

10. Simonsen L, Taylor RJ, Viboud C, Miller MA, Jackson LA. Mortality benefits of influenza vaccination in elderly people: an ongoing controversy. Lancet Infect Dis. 2007;7(10):658-66.
11. Rivetti D, Jefferson T, Thomas R, Rudin M, Rivetti A, Di Pietrantonj C, et al. Vaccines for preventing influenza in the elderly. Cochrane Database Syst Rev. 2006;3:CD004876.

12. Jackson LA, Nelson JC, Benson P, Neuzil KM, Reid RJ, Psaty BM, et al. Functional status is a confounder of the association of influenza vaccine and risk of all cause mortality in seniors. Int J Epidemiol. 2006;35(2):345-52.

13. Van Essen GA, Palache AM, Forleo E, Fedson DS. Influenza vaccination in 2000 recommendations and vaccine use in 50 developed and rapidly developing countries. Vaccine. 2003;21:1780-5.

14. Kroneman M, Paget WJ, van Essen GA. Influenza vaccination in Europe: an inventory of strategies to reach target populations and optimise vaccination uptake. Euro Surveill. 2003;8(6):pij=418. Available online: http://www. eurosurveillance.org/ViewArticle. aspx?ArticleId $=418$

15. Macroepidemiology of Influenza Vaccination (MIV) Study Group. The macroepidemiology of influenza vaccination in 56 countries, 1997--2003. Vaccine. 2005;23(44):5133-43.

16. Kroneman M, Van Essen GA, Paget WJ. Influenza vaccination coverage and reasons to refrain among high-risk persons in four European countries. Vaccine. 2006;24(5):622-8.

17. Szucs T, Müller D. Influenza vaccination coverage rates in five European countries - a population-based cross-sectional analysis of two consecutive influenza seasons. Vaccine. 2005;23(43):5055-563.

18. Fleming DM, Van der Velden JK, Paget WJ. The evolution of influenza surveillance in Europe and prospects for the next ten years. Vaccine. 2003;21(16):1749-53.

19. Lopalco PL, Lévy-Bruhl D, Salmaso S, Pastore Celentano L, Ferro A, Tridente G Appelgren E, O'Flanagan D. VENICE: Europe's new network for vaccination. Euro Surveill. 2007;12(3):pii=3116. Available online: http://www.eurosurveillance. org/ViewArticle.aspx?ArticleId $=3116$

20. Influenza Vaccination Programme: Winter 2005/06. Health Protection Agency. Communicable Diseases Monthly Report, Northern Ireland Edition 2006;15(3):8-10. Available from: http://www.cdscni.org.uk/publications/ MonthlyReports/Volume_15_2006/MonthlyReportVol15No3.pdf

21. O'Reilly D, Gormley G, Gilliland A, Cuene-Grandidier H, Rafferty C, Reilly P, et al. Influenza vaccinations in Northern Ireland: are older patients missing out? Age Ageing. 2002;31(5):385-90.

22. Joseph C, Goddard N. Influenza vaccine uptake in the elderly: results from a rapid assessment of the effectiveness of new government policy in England for the winters 2000/2001 and 2001/2002. Vaccine. 2003;21(11-12):1137-48.

23. Joseph C, Goddard N, Gelb D. Influenza vaccine uptake and distribution in England and Wales using data from the General Practice Research Database, 1989/90 - 2003/04. J Public Health (Oxf). 2005;27(4):371-7.

24. Tacken M, Verheij R, Mulder J, van den Hoogen H, Braspenning J. Monitoring griepvaccinatiecampagne 2003 [Monitoring the influenza vaccination campaign 2003]. Utrecht: Nivel; 2004. Available from: http://www.nivel.nl/pdf/LINHmonitor-griepvaccinatiecampagne-2003.pdf

25. Kempkens L. De griepvaccinatie van risicogroepen in Nederland [The influenza vaccination of high-risk groups in the Netherlands]. Maandbericht Gezondheidsstatistiek 1996;15(1):4-10.

26. Muller D, Nguyen-Van-Tam JS, Szucs TD. Influenza vaccination coverage rates in the UK: a comparison of two monitoring methods during the 2002-2003 and 2003-2004 seasons. Public Health 2006;120(11):1074-80.

27. Martin LM, Leff M, Calonge N, Garrett C, Nelson DE. Validation of self-reported chronic conditions and health services in a managed care population. Am J Prev Med. 2000;18(3):215-8.

28. Mac Donald R, Baken L, Nelson A, Nichol KL. Validation of self-report of influenza and pneumococcal vaccination status in elderly outpatients. Am J Prev Med. 1999;16(3):173-7.

29. Sheridan CL, Mulhern M, Martin D. Validation of a self-report measure of somatic health. Psychol.Rep. 1998;82(2):679-87.

30. Lampe FC, Walker M, Lennon LT, Whincup PH, Ebrahim S. Validity of a self-reported history of doctor-diagnosed angina. J Clin Epidemiol. 1999;52(1):73-81.

31. Kroneman MW, Van Essen GA, Tacken MAJB, Paget WJ, Verheij R. Does a population survey provide reliable influenza vaccine uptake rates among high-risk groups? A case study of the Netherlands. Vaccine. 2004;22(17-18):2163-70.

32. Influenza vaccines: WHO position paper. Weekly Epidemiological Record 2005;80(33):279-87. Available from: http://www.who.int/wer/2005/wer8033.pdf

This article was published on 15 May 2008

Citation style for this article: Kroneman M, Paget WJ, Meuwissen LE, Joseph C, Kennedy H. An approach to monitoring influenza vaccination uptake across Europe. Euro Surveill. 2008;13(20):pii=18874. Available online: http://www.eurosurveillance.org/ViewArticle. aspx?ArticleId $=18874$ 